Applied Microbiology and Biotechnology 2014

http://link.springer.com/article/10.1007/s00253-014-6090-z

\title{
Phenotypic evaluation of natural and industrial Saccharomyces yeasts for different traits desirable in industrial bioethanol production
}

\author{
Vaskar Mukherjee ${ }^{1,3 \#}$, Jan Steensels ${ }^{2 \#}$, Bart Lievens ${ }^{1}$, Ilse Van de Voorde ${ }^{3}$, Alex Verplaetse ${ }^{3}$, Guido \\ Aerts $^{3}$, Kris A. Willems ${ }^{1}$, Johan M. Thevelein ${ }^{4}$, Kevin J. Verstrepen ${ }^{2}$ and Stefan Ruyters ${ }^{1^{*}}$
}

Abstract Saccharomyces cerevisiae is the organism of choice for many food and beverage fermentations because it thrives in high-sugar and high-ethanol conditions. However, the conditions encountered in bioethanol fermentation pose specific challenges, including extremely high sugar and ethanol concentrations, high temperature and the presence of specific toxic compounds. It is generally considered that exploring the natural biodiversity of Saccharomyces strains may be an interesting route to find superior bioethanol strains and may also improve our understanding of the challenges faced by yeast cells during bioethanol fermentation. In this study, we phenotypically evaluated a large collection of diverse Saccharomyces strains on six selective traits relevant for bioethanol production with increasing stress intensity. Our results demonstrate a remarkably large phenotypic diversity among different Saccharomyces species and among S. cerevisiae strains from different origins. Currently applied bioethanol strains showed a high tolerance to many of these relevant traits, but several other natural and industrial S. cerevisiae strains outcompeted the bioethanol strains for specific traits. These multitolerant strains performed well in fermentation experiments mimicking industrial bioethanol production. Together, our results illustrate the potential of phenotyping the natural biodiversity of yeasts to find superior industrial strains that may be used in bioethanol production or can be used as a basis for further strain improvement through genetic engineering, experimental evolution, or breeding. Additionally, our study provides a basis for new insights into the relationships between tolerance to different stressors.

Key words bioethanol, fermentation, high-throughput, phenotype, Saccharomyces spp., stress tolerance

${ }^{1} \mathrm{KU}$ Leuven, Laboratory for Process Microbial Ecology and Bioinspirational Management, Cluster for Bioengineering Technology (CBeT), Department of Microbial and Molecular Systems (M2S), Campus De Nayer, Fortsesteenweg 30A, B-2860 Sint-Katelijne-Waver, Belgium

${ }^{2}$ KU Leuven, Laboratory for Genetics and Genomics \& VIB Laboratory for Systems Biology, Centre of Microbial and Plant Genetics (CMPG), Department of Microbial and Molecular Systems (M2S), Gaston Geenslaan 1, B-3001 Leuven, Belgium

${ }^{3} \mathrm{KU}$ Leuven, Laboratory of Enzyme, Fermentation, and Brewing Technology, Cluster for Bioengineering Technology (CBeT), Department of Microbial and Molecular Systems (M2S), Campus KaHo Sint-Lieven, Gebroeders De Smetstraat 1, B-9000 Ghent, Belgium

${ }^{4}$ KU Leuven, Laboratory of Molecular Cell Biology, Institute of Botany and Microbiology, and VIB Department of Molecular Microbiology, Kasteelpark Arenberg 31, B-3001 Leuven,Belgium

"These authors contributed equally

*corresponding author: stefan.ruyters@kuleuven.be Tel +3215305597 Fax +3215305599 


\section{Introduction}

Taxonomic analysis of the microbiota present in spontaneous alcoholic fermentation processes, such as the fermentation of fruit juice, beer wort, honey or cocoa, revealed a huge yeast diversity, with one yeast species dominating most of the fermentation processes, namely the ascomycetous yeast Saccharomyces cerevisiae (Pando Bedriñana et al. 2010; Bokulich et al. 2014; Meersman et al. 2013; Pretorius 2000; Steensels et al. 2014). This dominance has been studied intensively, and it was established that $S$. cerevisiae developed several mechanisms that caused a selective advantage in sugar-rich, alcoholic fermentation-like environments. For example, the Crabtree effect (in which glucose represses respiration) in S. cerevisiae is the basis for the so-called "make-accumulate-consume" strategy, where ethanol is first produced to inhibit the growth of other microorganisms, and is later consumed when all fermentable sugars are depleted (Thomson 2005). Furthermore, its ability to grow in both aerobic and anaerobic conditions and its very high glycolytic flux enables it to thrive in all stages of the fermentation process and restrain competing microorganisms (Conant and Wolfe 2007; Goddard 2008; Piškur et al. 2006). Interestingly, the majority of these "fermentative features" emerged not as a response to a man-made fermentation environment, but rather in response to the emergence of angiosperms and fleshy fruits that offered a novel carbon resource worth defending by ethanol accumulation (Thomson et al. 2005; Voordeckers et al. 2012). However, it is well accepted that human intervention has evolved wild $S$. cerevisiae strains into distinct domesticated variants (Diezmann and Dietrich 2009; Fay and Benavides 2005; Steensels and Verstrepen 2014). Examples of traits acquired during domestication include increased copper tolerance (Warringer et al. 2011), flavour production (Hyma et al. 2011) and fructose fermentation capacity (Novo et al. 2009) for wine strains, or an industrially favorable flocculation behavior (Verstrepen et al. 2003) and improved maltose utilization (Voordeckers et al. 2012) in brewing strains. As a result, there are currently several non-domesticated ("wild") and domesticated ("industrial") genetic lineages of S. cerevisiae (Liti et al. 2009). These lineages are often not strictly genetically or geographically separated. Indeed, recent genome-wide analysis of the $S$. cerevisiae biodiversity revealed that man-mediated dispersal of this species allowed intercrossing of different lineages generated strains with mosaic genomes that inherited traits from both parental lineages (Diezmann and Dietrich 2009; Legras et al. 2007; Liti et al. 2009). This peculiar genomic structure is not encountered in non-domesticated species, such as the $S$. paradoxus, which is genetically closely related to $S$. cerevisiae.

Compared to e.g. beer, bread or wine fermentations, bioethanol production is a relatively new man-made fermentation process. The bioethanol environment confronts yeasts with new, very specific challenges, which differ greatly from conditions commonly encountered in the traditional 
food and beverage fermentations. More specifically, the implementation of very high gravity fermentation with initial sugar concentrations above $300 \mathrm{~g} \mathrm{I}^{-1}$ to increase cost efficiency requires osmotolerant and ethanol tolerant yeast strains (Pais et al. 2013; Puligundla et al. 2011; Tao et al. 2012; Watanabe et al. 2010). Salt tolerance is important in ethanol production with molasses (Basso et al. 2011). In second-generation bioethanol production with lignocellulose hydrolysates, typical stressors include furfural and 5-hydroxymethylfurfural (5-HMF) originating from the dehydration of pentoses and hexoses, respectively, weak acids formed by the degradation of furfural and 5-HMF (Almeida et al. 2007; Palmqvist and Hahn-Hägerdal 2000, Taylor et al. 2012), acetic acid due to cleavage of acetyl groups from the xylan backbone of the hemicelluloses fraction (Chen et al. 2012), phenolic compounds released due to partial breakdown of lignin (Almeida et al. 2011) and heavy metal contaminants. Lastly, strains are often subjected to thermal stress during the fermentation process, which is caused by the metabolic activity of the yeasts and/or by high environmental temperatures (Basso et al. 2011; Kumar et al. 2013).

Several studies aimed to improve the efficiency of $S$. cerevisiae strains for first- and secondgeneration bioethanol production by targeting one or few specific traits of interest, such as tolerance to inhibitors or pentose fermentation, e.g. by quantitative trait locus (QTL) analysis, mutagenesis, genome shuffling, metabolic and evolutionary engineering or a combination of these techniques (Demeke et al. 2013; Hubmann et al. 2013; Koppram et al. 2012; Kumari and Pramanik 2012; Pais et al. 2013; Pinel et al. 2011; Shi et al. 2009; Swinnen et al. 2012; Tao et al. 2012). Moreover, several recent studies focus on investigating the potential of wild or other industrial S. cerevisiae strains for bioethanol production (Jin et al. 2013; Pereira et al. 2014; Ramos et al. 2013; Wimalasena et al. 2014). Indeed, in the Brazilian bioethanol production with yeast recycling, regular baker's yeast strains initially used as bioethanol fermentations starters were quickly outcompeted by invading wild strains. They dominated and persisted much better in the recycling system than any domesticated yeast strain (Basso et al. 2008; da Silva-Filho et al. 2005). This shows the potential of phenotyping the natural biodiversity of yeasts to find superior industrial bioethanol strains. However, many of these previously performed studies are limited by the number of targeted traits or by the number of studied strains, despite the advent of diverse high-throughput automated phenotypic screening platforms. Nevertheless, such information might be crucial for selection of new, multitolerant strains that can serve as efficient bioethanol production strains or as good candidates for further improvements by, for example, genetic or evolutionary engineering and/or breeding.

In this study, a comprehensive phenotypic evaluation of a large collection of Saccharomyces isolates belonging to different species was performed for six stress tolerance traits important for bioethanol production. Studied isolates originated from different habitats and were subjected to 
increasing stress intensities in order to map the phenotypic diversity among different Saccharomyces species and among S. cerevisiae strains from different origins. The most multitolerant strains were selected for fermentation experiments mimicking industrial bioethanol production.

\section{Materials and methods}

Yeast collection

A large culture collection, consisting of 373 industrial and wild Saccharomyces isolates from diverse origins and belonging to S. cerevisiae (279), S. pastorianus (46), S. paradoxus (38) and S. bayanus (10), was used in this study (Table 1). Isolates were identified to the species level by sequencing the variable D1/D2 domain of the large-subunit (26S) ribosomal RNA gene as described by Kurtzman and Robnett (1997). The majority of strains (276) originated from diverse industrial food fermentations, such as ale (122, all S. cerevisiae), lager (47, all S. pastorianus except one), wine (71, all S. cerevisiae except one $S$. bayanus), sake $(15$, all S. cerevisiae), spirit $(12$, all $S$. cerevisiae) or bakery $(9$, all S. cerevisiae). Additionally, eight $S$. cerevisiae strains that are currently applied in commercial bioethanol production were included. Further, the collection consisted of 82 wild isolates (no S. pastorianus) originating from various natural environments, such as oak bark and spontaneous cocoa fermentations, and a number of laboratory yeast strains, including S288c (Mortimer and Johnston 1986) and SK1 (Kane and Roth 1974). All isolates were stored at $-80{ }^{\circ} \mathrm{C}$ in glycerol based standard storage medium ( $2 \% \mathrm{w} / \mathrm{v}$ bacto peptone, $1 \% \mathrm{w} / \mathrm{v}$ yeast extract, $25 \% \mathrm{v} / \mathrm{v}$ glycerol) in $96-$ well microtiter plates. Five strains from different origins were present in each microtiter plate as a control for inter-experiment variation.

Genotyping

All isolates were characterized at strain level by interdelta typing according to Legras and Krast (2003), employing the primers delta12 (5'-TCAACAATGGAATCCCAAC- $3^{\prime}$ ) and delta21 (5'CATCTTAACACCGTATATGA-3'). Genomic DNA was extracted as described previously (Meersman et al. 2013). PCR amplification was performed in a reaction volume of $20 \mu \mathrm{l}$, containing $200 \mathrm{mM}$ of each dNTP, $1 \mu \mathrm{M}$ of each primer, 5 units ExTaq polymerase, 1x ExTaq Buffer (Takara, Otsu, Shiga Japan), and $5 \mathrm{ng}$ genomic DNA. Amplification was performed using a C1000 thermal cycler (Biorad, Hercules, California USA) according to the following thermal profile: initial denaturation at $95{ }^{\circ} \mathrm{C}$ for $3 \mathrm{~min}$, followed by 9 cycles of $94^{\circ} \mathrm{C}$ for $25 \mathrm{~s}, 45^{\circ} \mathrm{C}$ for $30 \mathrm{~s}$ and $72{ }^{\circ} \mathrm{C}$ for $90 \mathrm{~s}$, and 21 cycles of $94{ }^{\circ} \mathrm{C}$ for $25 \mathrm{~s}$, $50{ }^{\circ} \mathrm{C}$ for $30 \mathrm{~s}$ and $72{ }^{\circ} \mathrm{C}$ for $90 \mathrm{~s}$. A final elongation step of $10 \mathrm{~min}$ at $72{ }^{\circ} \mathrm{C}$ was performed. Amplification products were separated by agarose gel electrophoresis (7 $\mathrm{min}, 5 \mathrm{kV}$ ) on a QIAxcel Advanced System (Qiagen, Venlo, Limburg Netherlands). 


\section{Test conditions and media preparation}

Unless mentioned otherwise, all materials used for media preparation were purchased from Sigma-Aldrich (St. Louis, Missouri USA). All isolates were evaluated for (i) sugar- and/or osmotolerance using increasing concentrations of glucose (ranging from $40 \%$ to $70 \% \mathrm{w} / \mathrm{v}$ ), fructose $(40 \%-70 \% \mathrm{w} / \mathrm{v})$ and sorbitol $(30 \%-55 \% \mathrm{w} / \mathrm{v})$, (ii) halotolerance using increasing concentrations of $\mathrm{NaCl}(500 \mathrm{mM}$ - $3000 \mathrm{mM}), \mathrm{KCl}(1000 \mathrm{mM}-4000 \mathrm{mM})$ and $\mathrm{LiCl}(10 \mathrm{mM}-600 \mathrm{mM})$, (iii) ethanol tolerance using increasing concentrations of ethanol (5\% - 15\% v/v), (iv) furan derivative tolerance using increasing concentrations of 5-HMF $\left(2 \mathrm{~g} \mathrm{l}^{-1}-7 \mathrm{~g} \mathrm{l}^{-1}\right)$, and $(\mathrm{v})$ metal tolerance using increasing concentrations of $\mathrm{ZnCl}_{2}(1 \mathrm{mM}-10 \mathrm{mM}), \mathrm{CuSO}_{4}(0.1 \mathrm{mM}-2 \mathrm{mM})$ and $\mathrm{CdSO}_{4}(0.25 \mathrm{mM}-3 \mathrm{mM})$. Concentrations were selected based on Saccharomyces tolerance limits described in literature and can be found in Table S1 (Supplementary Information). For all trait evaluations, YPD agar plates (1.5\% w/v agar (Invitrogen, Carlsbad, California USA); 2\% w/v bacto peptone (Becton Dickinson, East Rutherford, New Jersey USA); $1 \% \mathrm{w} / \mathrm{v}$ yeast extract (LabM, Heywood, Lancashire UK) and 2\% w/v glucose) were used, supplemented with the test compound. Additionally, isolates were incubated on YPD agar without test compound as a control. Further, isolates were tested for thermotolerance (24 ${ }^{\circ} \mathrm{C}-41^{\circ} \mathrm{C}$ ) on this medium. Carbon and nitrogen sources were autoclaved separately to avoid Maillard reactions, and mixed when the temperature dropped to about $50{ }^{\circ} \mathrm{C}$. Ethanol and $5-\mathrm{HMF}$ were also added after autoclaving.

Phenotypic screening

In order to maximize throughput and reproducibility, a high-density array robot (ROTOR HDA, Singer Instruments, Roadwater, Somerset UK) was used to produce and replicate high-density arrays of the yeast collection on the different test media. More specifically, first, the 96-well microtiter plates containing the stored isolates were thawed and spotted on YPD agar and incubated at $30{ }^{\circ} \mathrm{C}$ for 48 h. Next, 96-well plates containing $150 \mu$ l of standard YPD medium (2\% w/v Bacto peptone; $1 \%$ $\mathrm{w} / \mathrm{v}$ yeast extract, and $2 \% \mathrm{w} / \mathrm{v}$ glucose) in each well were inoculated with the isolates using the robot and incubated overnight at $30{ }^{\circ} \mathrm{C}$ on a microplate shaking platform (Heidolph, Schwabach, Bavaria Germany) at $900 \mathrm{rpm}$. In case of screening for ethanol tolerance, isolates were precultured for $48 \mathrm{~h}$ in YPD medium with $2 \%$ ethanol $(\mathrm{v} / \mathrm{v})$ for preconditioning. Then, the optical density at $600 \mathrm{~nm}\left(\mathrm{OD}_{600}\right)$ of all wells was measured using a microplate reader (Molecular Devices, Sunnyvale, California USA). Subsequently, cell density was manually adjusted to $O D_{600} \approx 0.2$ in a second 96 -well microtiter plate using sterile deionized water in order to standardize the starting cell concentration for all isolates. This plate was used as the source plate for spotting the test media. After spotting, all plates were sealed using parafilm and incubated at $30{ }^{\circ} \mathrm{C}$ (except for the thermotolerance assays). After five days 
of incubation all plates were scanned using a high definition scanner (Seiko Epson, Nagano, Japan). An example of the obtained pictures can be found in Supplementary Material Fig. S2.

\section{Data analysis}

For each isolate, a phenotypic profile was obtained by assessment of the colony size on the different test media relative to the growth on the control medium (YPD agar), containing no test compounds. For that purpose, scanned images were processed using ImageJ (Abramoff et al. 2004), combined with the ScreenMill software (Dittmar et al. 2010) especially developed for this purpose. Relative growth was calculated as the growth at a certain trait concentration ("test condition") relative to the growth on the control medium. Growth under a test condition is only considered when the relative growth exceeds $5 \%$ of the growth on the control medium. The relative growth was further processed by an inverse hyperbolic sine transformation, followed by conversion into Z-scores, which is a statistical measurement of a score's relationship to the mean in a group of scores:

$$
Z \text {-score }=\frac{(X-\mu)}{\sigma}
$$

with $X=$ transformed relative growth for a particular strain under a particular test condition; $\mu=$ mean transformed relative growth for all isolates for a particular test condition; $\sigma=$ standard deviation of transformed values for all isolates for a particular test condition.

Both genotypic and phenotypic profiles obtained were processed using BioNumerics (Applied Maths, Sint-Martens-Latem, Belgium). Clustering of the isolates based on genotype was established using a combination of the Dice coefficient (for generating the similarity matrix) and the Unweighted Pair Group Method with Arithmetic Mean (UPGMA) clustering algorithm. Clustering of the isolates based on phenotype was performed using the Pearson coefficient (for generating the similarity matrix) and the UPGMA algorithm. The equality of overall phenotypic variation among different species and between domesticated and non-domesticated isolates was estimated by calculating the coefficient of variation among isolates at different reference concentrations followed by student's two tailed paired t-test to check for any statistically significant difference ( $p$ value $<0.05$ ).

Maximal tolerance limits were defined for each species, and for origin of isolation by the stress concentrations at which at least $10 \%$ of the strains showed $>5 \%$ relative growth. Additionally, for each trait a "reference concentration" was determined (Supplementary Material Table S2) as the concentration where approximately $50 \%$ of the investigated isolates managed to grow and showed the highest coefficient of variation. These reference concentrations should therefore be the best concentrations to position isolates in comparison with the whole isolates set. Spearman correlation coefficients were calculated among reference concentrations for each tested trait using SAS software (SAS 9.3, SAS Institute, USA). Further, results were visualized by density plots ("bean plots") using R 
for each reference concentration (R Development Core Team, 2013). The pairwise Wilcoxon test for equality of means, combined with the Holm correction for multiple testing, and the Levene's test for equality of variances were performed using $\mathrm{R}$ in order to detect significant differences between different isolation origins or between different species. These tests take into account the difference in the number of isolates among groups.

\section{Fermentation assays}

Seven strains with the best overall performance at high concentrations of glucose, 5-HMF, ethanol and at high temperature were selected and considered multitolerant. For these strains, fermentation experiments at $33 \%$ glucose $(\mathrm{w} / \mathrm{v})$ were performed to determine their fermentation potential in simulated $1^{\text {st }}$ generation high-gravity bioethanol production medium. Next, the two most promising strains (Y312 and $\mathrm{Y} 232$ ) were selected for fermentations in an artificial medium with $12 \%$ $\mathrm{w} / \mathrm{v}$ glucose and an inhibitor cocktail containing $1.02 \mathrm{~g} \mathrm{I}^{-1}$ 5-HMF, $0.33 \mathrm{~g} \mathrm{I}^{-1}$ furfural, $1.9 \mathrm{~g} \mathrm{I}^{-1}$ acetic acid, $0.36 \mathrm{~g} \mathrm{l}^{-1}$ formic acid, $0.7 \mathrm{~g} \mathrm{I}^{-1}$ levulinic acid and $0.033 \mathrm{~g} \mathrm{I}^{-1}$ vanillin, mimicking the inhibitor concentrations in lignocellulose hydrolysates (Koppram et al. 2012). Similar fermentations were also performed without inhibitors. Fermentation parameters were compared with those of commercial bioethanol production strains (Ethanol Red and CAT1). The $\mathrm{CO}_{2}$ production rate $\left(\mathrm{g} \mathrm{l}^{-1} \mathrm{~h}^{-1}\right)$ was calculated using cubic spline fitting function (Prism 6.04, Graph Pad Software, San Diego California, USA). Lab strain S288c and ale strain Y1 were used as references for strains performing weakly in our high-throughput phenotypic evaluation. Strains were precultured overnight in $3 \mathrm{ml}$ control medium containing $2 \%$ glucose at $30{ }^{\circ} \mathrm{C}$. Subsequently, $50 \mathrm{ml}$ YP medium containing $10 \%$ glucose was inoculated with the strains at a starting $\mathrm{OD}_{600}$ of 0.75 and incubated at $30^{\circ} \mathrm{C}, 200 \mathrm{rpm}$ for two days until stationary phase. Next, $\mathrm{OD}_{600}$ of the precultures was measured and fermentation tubes were inoculated at a final $\mathrm{OD}_{600}$ of 2.5 (for $33 \%$ glucose) or 0.75 (for artificial fermentation medium mimicking the inhibitor concentrations in lignocellulose hydrolysates) in a total volume of $80 \mathrm{ml}$. Semi-anaerobic batch fermentation were performed in cylindrical glass tubes with a rubber stopper containing a cotton plugged glass pipe to release $\mathrm{CO}_{2}$. The fermentations were continuously stirred at $120 \mathrm{rpm}$. This system has been used frequently to mimic the industrial fermentation conditions (Demeke et al. 2013; Hubmann et al. 2013). The weight loss of the tubes due to $\mathrm{CO}_{2}$ release was used to follow the course of fermentation. Fermentations were performed in duplicate. At the end of the fermentation (when the $\mathrm{CO}_{2}$ production rate dropped below $0.01 \mathrm{~g} \mathrm{l}^{-1} \mathrm{~h}^{-1}$ ), $1 \mathrm{ml}$ samples of the fermentation medium were taken, centrifuged and the concentration of ethanol was determined in the supernatant using high performance liquid chromatography (HPLC, Waters isocratic Breeze, ion exchange column WAT010290; Demeke et al. 2013). Column temperature was maintained at $75^{\circ} \mathrm{C} .5$ 
$\mathrm{mM} \mathrm{H}_{2} \mathrm{SO}_{4}$ was used as eluent with a flow rate of $1 \mathrm{ml} \mathrm{min}^{-1}$. A refractive index detector (Waters 2410, Waters, Milford, Massachusetts USA) was used to quantify the compounds of interest.

\section{Results}

Genetic and phenotypic diversity within the Saccharomyces isolates collection

Genotyping by PCR-based fingerprinting (interdelta analysis) showed that this collection consists of genetically very diverse isolates. Interestingly, S. cerevisiae did not show clearly distinguishable clusters of isolates from different origins (Supplementary Material Fig. S1) except for a separate cluster of ale isolates. Isolates from other origins did not cluster clearly, which is indicative of a broad genetic diversity within the collection. The color gradient in the phenotypic clustering in Fig. 1 shows the tolerance of each S. cerevisiae isolate to a given stress concentration, with green being most tolerant and red as least tolerant. The variation in color and color intensities within each column in Fig. 1 demonstrates the vast phenotypic diversity for each of the tested stress concentrations among S. cerevisiae isolates. Relative growth of all isolates on all parameters is given in Supplementary Material Table S3. No significant difference in the overall phenotypic diversity was observed between the species S. paradoxus and S. cerevisiae (student's two tailed paired t-test, $p=0.62$ ). However, for specific traits the diversity of the $S$. paradoxus isolates was significantly (Levene's test for equality of variances, $p<0.05$ ) lower than that of the $S$. cerevisiae strains, e.g. under osmostress (39\% difference in coefficient of variance), $\mathrm{NaCl}$ stress (27\%), $\mathrm{KCl}$ stress (55\%), $\mathrm{Cd}$ stress $(71 \%)$, while the diversity of the $S$. cerevisiae isolates was significantly lower than that of the $S$. paradoxus isolates for $\mathrm{LiCl}$ stress (30\%), ethanol stress (17\%), thermal stress $(77 \%)$ and $\mathrm{Cu}$ stress (49\%). Additionally, the overall phenotypic diversity among the non-domesticated (wild) S. cerevisiae isolates was found to be $6 \%$ less than the domesticated S. cerevisiae isolates.

Comparison of stress tolerance between different Saccharomyces species

A significant and very high correlation ( $r=0.78-0.85$, Table 3 ) between tolerance to the three different osmolytes used in this study (glucose, fructose and sorbitol) was observed. Therefore, only osmotolerance in glucose medium will be discussed henceforward. S. pastorianus was the least tolerant to all stress factors compared to the other species (Table 1 and Fig. 2) and in particular for osmostress, ethanol stress and 5-HMF stress. S. paradoxus generally grew better compared to the other species in high osmolyte concentrations, e.g. $76 \%$ of the isolates (29 isolates) managed to grow in $48 \%$ glucose $(\mathrm{w} / \mathrm{v})$ (reference concentration), compared to only $13 \%$ (6 strains) of S. pastorianus, $55 \%$ (153 isolates) of S. cerevisiae and 60\% (6 strains) of S. bayanus isolates. Similarly, significant differences were noticed in the $\mathrm{KCl}$ tolerance assay (Fig. 2 and Table S4A), in which 97\% (37) of S. paradoxus isolates exhibited growth at the reference concentration compared to $26 \%$ (12) of 


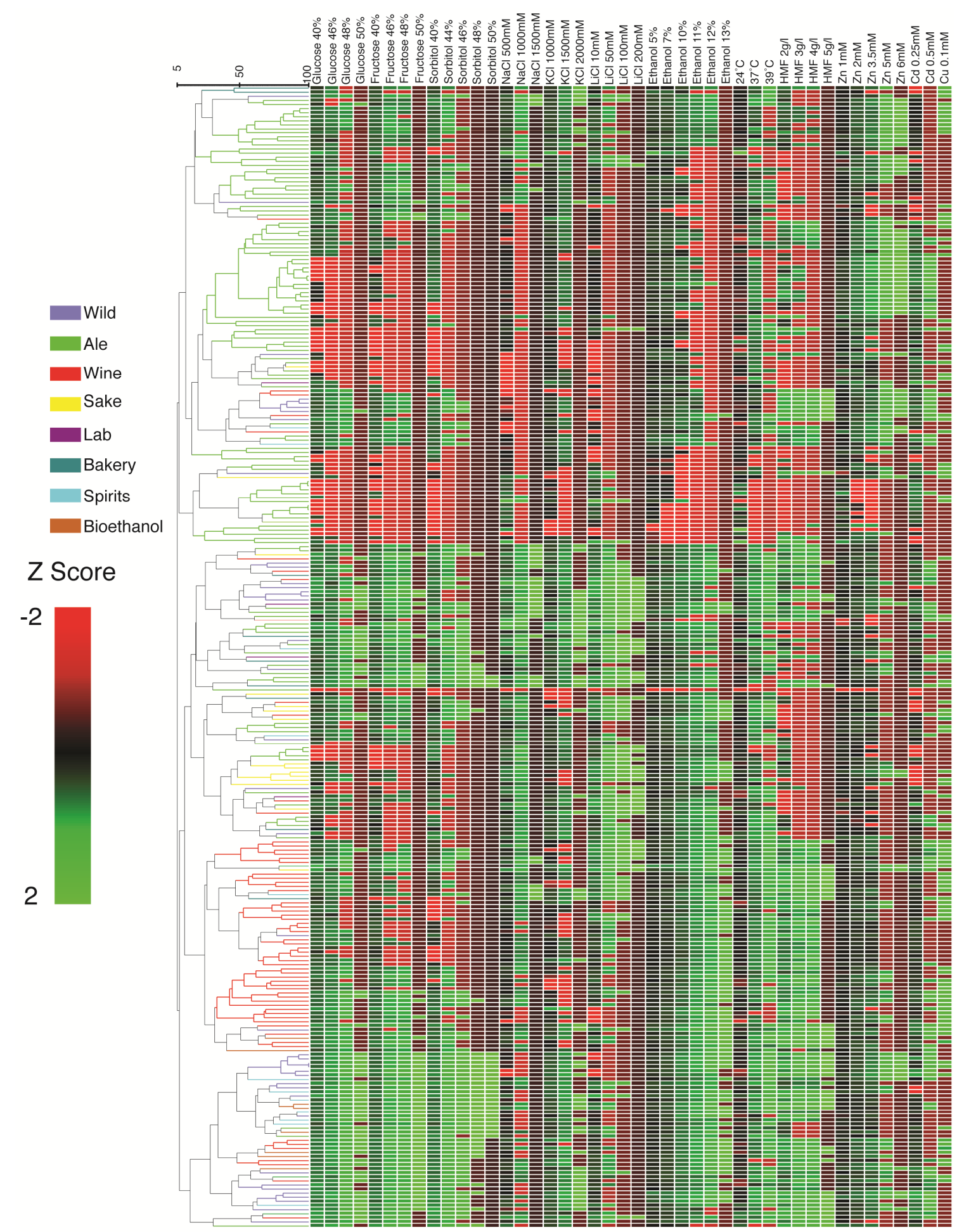

Fig. 1: UPGMA phenotypic clustering using the Pearson coefficient of the relative growth of the Saccharomyces cerevisiae isolates for all stress conditions investigated in this study. Isolates from different origins are marked in different colors (see figure for color legend). High tolerance is marked as green, while low tolerance is marked with red. The variation in color and color intensities demonstrates the vast phenotypic diversity for each of the tested stress concentrations among $S$. cerevisiae isolates. 
S. pastorianus, $40 \%$ of S. bayanus (4) and $75 \%$ (209) of S. cerevisiae. Interestingly, osmotolerance and $\mathrm{KCl}$ tolerance were correlated $(r=0.42)$, while only a weak positive correlation $(r=0.14-0.15)$ was identified with other salt stressors, i.e. $\mathrm{NaCl}$ and $\mathrm{LiCl}$, which however were highly correlated with each other $(r=0.72$ ) (Table 2). S. cerevisiae and S. bayanus were both significantly more tolerant to ethanol compared to S. paradoxus and S. pastorianus (Fig. 2 and Table S4A), with isolates tolerating up to $14 \%$ ethanol $(\mathrm{v} / \mathrm{v})$, whereas the latter species was limited to $12 \%$ ethanol $(\mathrm{v} / \mathrm{v})$ (Table 1$)$. On average, 5-HMF tolerance was similar among all species except $S$. pastorianus of which almost all strains were inhibited at the reference concentration $\left(3 \mathrm{gl}^{-1}\right)$. In contrast, even at $4 \mathrm{gl}^{-1} 5-\mathrm{HMF}$, nearly $50 \%$ of the $S$. cerevisiae isolates showed growth and 12 isolates managed to grow up to $7 \mathrm{gl}^{-1} 5$-HMF. In case of metal tolerance, trends were dependent on the metal tested. Tolerance to $\mathrm{Zn}$ was similar among species with growth observed up to $6 \mathrm{mM}$ for S. cerevisiae, S. paradoxus and S. pastorianus. In case of $\mathrm{Cd}$, S. paradoxus showed significantly higher tolerance compared to the other species, whereas S. bayanus was significantly more tolerant to Cu stress (Fig. 2). Interestingly, at low Zn and $\mathrm{Cu}$ concentrations, a large number of isolates showed better growth than on the control plate. For example, at $0.1 \mathrm{mM} \mathrm{CuSO}_{4}$ and $0.1 \mathrm{mM} \mathrm{ZnCl}_{2}, 77 \%$ and $52 \%$ of the isolates, respectively, showed better growth compared to the control condition. Finally, S. cerevisiae was significantly more thermotolerant than S. paradoxus and S. pastorianus with $62 \%$ of the isolates (173 isolates) growing at $39{ }^{\circ} \mathrm{C}$ compared to only $5 \%$ (2) and $15 \%$ (7), respectively (Fig. 2).

\section{Comparison of stress tolerance between Saccharomyces cerevisiae isolates from different origins}

In terms of osmotolerance, the majority of isolates showed considerable growth inhibition (on average $70 \%$ inhibition of the growth) at $40 \%$ glucose (w/v) (the lowest concentration tested). In general, isolates from ale, bakery and sake were less tolerant to high sugar concentrations compared to isolates from other origins (Fig. 3). For example, bioethanol, wine, spirits and wild isolates showed significantly higher osmotolerance at the reference concentration ( $48 \%$ glucose, $w / v$ ) compared to ale strains (Fig. 3 and Table S4B). In particular, seven wild isolates and one bioethanol isolate were exceptionally osmotolerant and showed considerable growth up to $55 \%$ glucose (w/v) (Table 1 ).

Wild isolates appeared to be significantly more tolerant to $\mathrm{KCl}$ than sake, ale and wine strains (Fig. 3 and Supplementary Material Table S4B). Although not observed for the selected reference concentration (1500 mM KCl; Fig. 3), bakery, bioethanol and spirits strains were also moderately $\mathrm{KCl}$ tolerant with nearly $50 \%$ of the strains that managed to grow at $2000 \mathrm{mM} \mathrm{KCl}$ (respectively 5,5 and 4 strains). Isolates from different origins were on average equally tolerant to $\mathrm{LiCl}$ except for sake strains that were significantly more tolerant compared to ale strains (Fig. 3). In addition, bakery strains showed the highest tolerance to $\mathrm{LiCl}$ with on average $78 \%$ of the isolates ( 7 strains) that managed to grow in the presence of $100 \mathrm{mM} \mathrm{LiCl}$. 

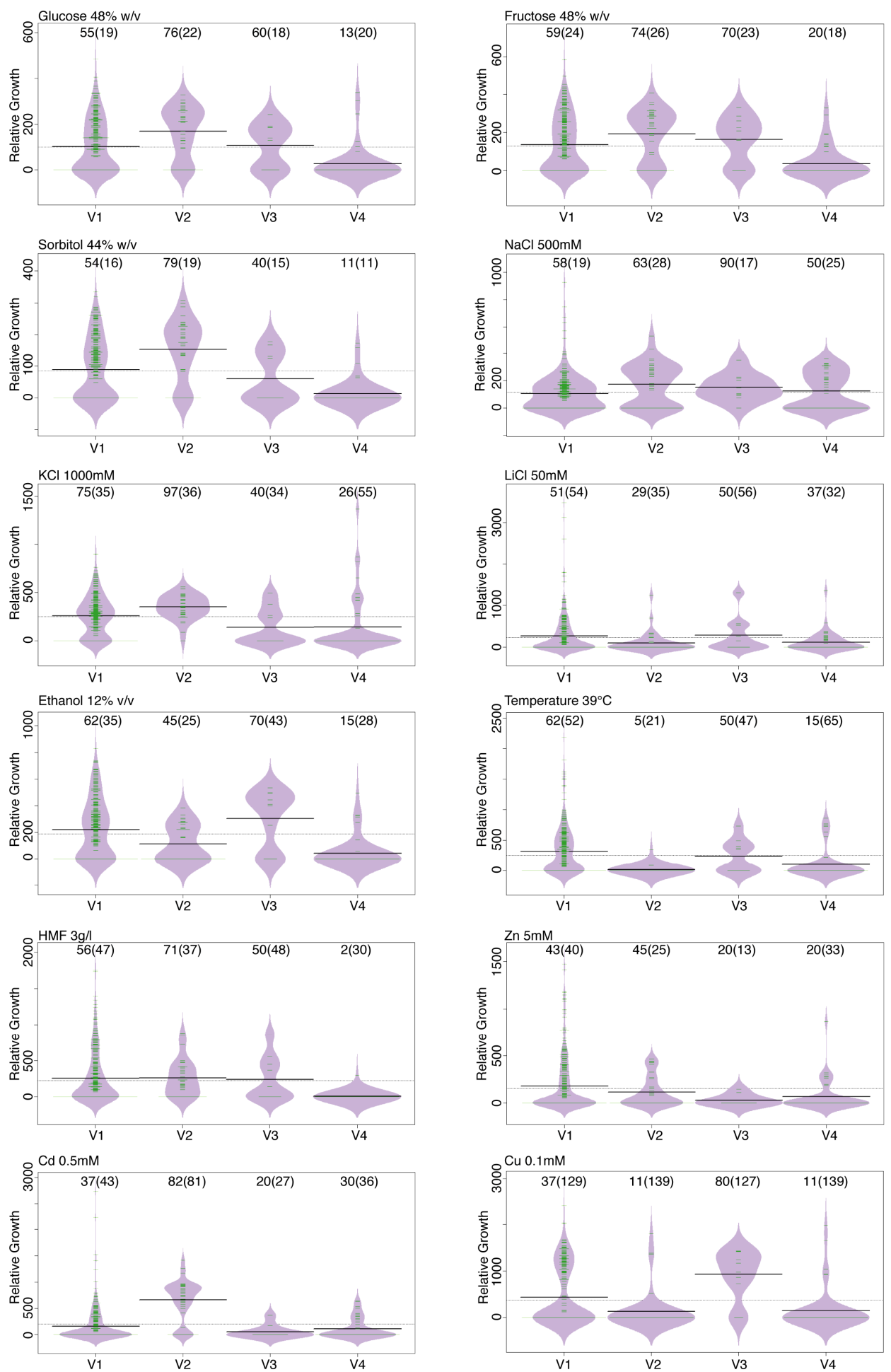

Fig. 2: Beanplots illustrating the relative growth (Y-axis) of strains of different Saccharomyces species in our collection under reference concentrations for each trait with V1: S. cerevisiae, V2: S. paradoxus, V3: S. bayanus, V4: S. pastorianus. The black line represents the average relative growth for each group, the dotted line that among all groups. The shape of the bean represents the distribution. Above each plot, the percentage of the number of strains growing at the reference concentrations with relative growth $>5 \%$ is indicated and within bracket the average relative growth (\%) of strains growing in the presence of the reference concentrations. 

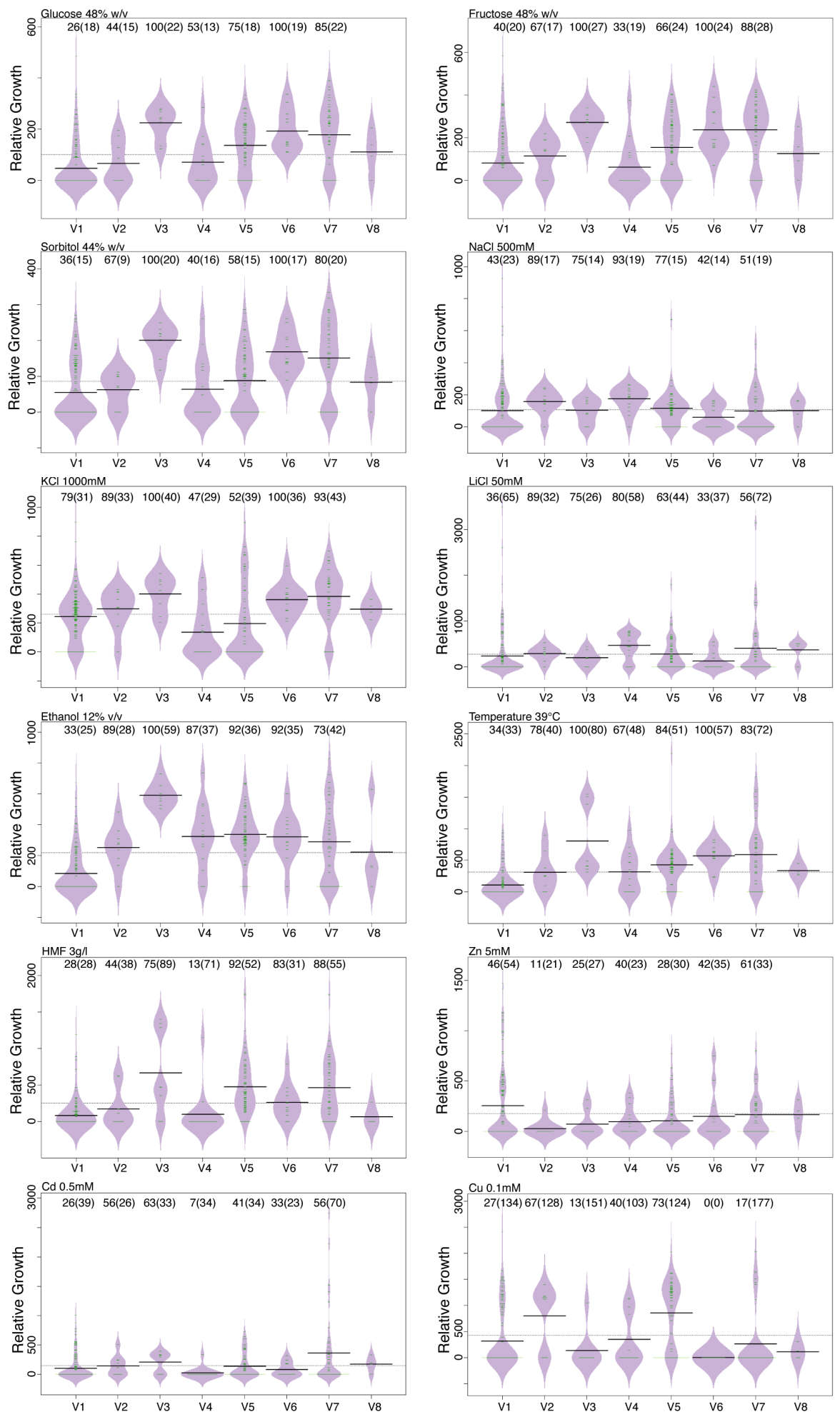

Fig. 3: Beanplots illustrating the relative growth of Saccharomyces cerevisiae strains coming from different origins in the presence of the reference concentrations, with V1: Ale, V2: Bakery, V3: Bioethanol, V4: Sake, V5: Wine, V6: Spirit, V7: Wild, V8: Lab. Above each plot, the percentage of the number of strains growing in the presence of the reference concentrations with relative growth $>5 \%$ is indicated and within brackets the average relative growth of strains growing in the presence of the reference concentrations. 
Table 1: Overview of the number of isolates and tolerance limits ${ }^{(a)}$ of different Saccharomyces species and for different origins of S. cerevisiae isolates in this study.

\begin{tabular}{|c|c|c|c|c|c|c|c|c|c|c|c|c|c|}
\hline & No of isolates & $\begin{array}{l}\text { Glucose } \\
w / v \%\end{array}$ & $\begin{array}{l}\text { Fructose } \\
w / v \%\end{array}$ & $\begin{array}{l}\text { Sorbitol } \\
w / v \%\end{array}$ & $\begin{array}{l}\mathrm{NaCl} \\
\mathrm{mM}\end{array}$ & $\begin{array}{l}\mathrm{KCl} \\
\mathrm{mM}\end{array}$ & $\begin{array}{l}\text { LiCl } \\
\mathrm{mM}\end{array}$ & $\begin{array}{l}\text { Ethanol } \\
v / v \%\end{array}$ & $\begin{array}{l}\text { Temp } \\
{ }^{\circ} \mathrm{C}\end{array}$ & $\begin{array}{l}\mathrm{HMF} \\
\mathrm{g} \mathrm{I}^{-1}\end{array}$ & $\begin{array}{l}\mathrm{ZnCl}_{2} \\
\mathrm{mM}\end{array}$ & $\begin{array}{l}\mathrm{CdSO}_{4} \\
\mathrm{mM}\end{array}$ & $\begin{array}{l}\mathrm{CuSO}_{4} \\
\mathrm{mM}\end{array}$ \\
\hline \multicolumn{14}{|l|}{ Species } \\
\hline S. cerevisiae & 279 & 50 & 50 & 48 & 1500 & 2000 & 200 & 14 & 39 & 5 & 6 & 0.5 & 0.2 \\
\hline S. paradoxus & 38 & 50 & 50 & 50 & 1000 & 2000 & 100 & 12 & 37 & 5 & 6 & 1 & 0.1 \\
\hline S. pastorianus & 46 & 50 & 48 & 44 & 1500 & 1500 & 100 & 12 & 39 & 2 & 6 & 0.5 & 0.1 \\
\hline S. bayanus & 10 & 48 & 48 & 46 & 1500 & 1500 & 200 & 14 & 39 & 5 & 5 & 0.5 & 0.1 \\
\hline \multicolumn{14}{|c|}{ Origin of S. cerevisiae isolates } \\
\hline Ale & 122 & 48 & 48 & 46 & 1000 & 2000 & 200 & 12 & 39 & 4 & 7 & 0.5 & 0.1 \\
\hline Wild & 41 & 55 & 55 & 50 & 1500 & 2000 & 200 & 13 & 39 & 7 & 6 & 0.5 & 0.1 \\
\hline Wine & 64 & 50 & 50 & 46 & 1500 & 1500 & 200 & 14 & 39 & 5 & 5 & 0.5 & 0.2 \\
\hline Sake & 15 & 48 & 48 & 48 & 1000 & 1500 & 200 & 14 & 39 & 4 & 6 & 0.25 & 0.2 \\
\hline Spirits & 12 & 50 & 50 & 50 & 1000 & 2000 & 100 & 13 & 39 & 5 & 6 & 0.5 & $<0.1$ \\
\hline Bakery & 9 & 50 & 50 & 50 & 1500 & 2000 & 200 & 12 & 39 & 5 & 5 & 0.5 & 0.2 \\
\hline Bioethanol & 8 & 55 & 55 & 50 & 1000 & 2000 & 50 & 14 & 39 & 6 & 6 & 0.5 & 0.1 \\
\hline \multicolumn{14}{|c|}{ Control and Industrial strains profiles } \\
\hline S288C & & 48 & 48 & 44 & 1000 & 2000 & 200 & 12 & 39 & $<2$ & 3.5 & 0.25 & 0.1 \\
\hline SK1 & & 46 & $<40$ & 40 & $<500$ & 1500 & $<10$ & 10 & 39 & $<2$ & 5 & 0.5 & $<0.1$ \\
\hline Ethanol Red & & 50 & 50 & 50 & 1000 & 2000 & 50 & 14 & 39 & 5 & 3.5 & 0.5 & $<0.1$ \\
\hline CAT1 & & 50 & 55 & 50 & 1000 & 2000 & 50 & 13 & 39 & 2 & 3.5 & 0.25 & $<0.1$ \\
\hline
\end{tabular}

(a) Tolerance limit is defined as the tested concentration of each trait at which at least $10 \%$ of the isolates exhibited $>5 \%$ growth. 
Table 3: Overview of the tolerance limit, growth (at reference concentrations) and fermentation parameters in $33 \%$ glucose of the selected multitolerant strains obtained in this study, two industrial bioethanol strains and two selected non-multitolerant strains.

\begin{tabular}{|c|c|c|c|c|c|c|c|c|c|c|c|c|}
\hline \multirow[t]{2}{*}{ Strain name } & \multirow[t]{2}{*}{ Origin } & \multicolumn{2}{|c|}{ Osmotolerance } & \multicolumn{2}{|c|}{ Ethanol Tolerance } & \multicolumn{2}{|c|}{ HMF Tolerance } & \multicolumn{2}{|c|}{ Thermotolerance } & \multicolumn{3}{|c|}{ Fermentation } \\
\hline & & $\begin{array}{l}\text { Tolerance } \\
\text { limit (\%) }\end{array}$ & $\begin{array}{c}\text { Growth } \\
\text { at } 48 \% \\
\text { Glucose } \\
\text { (\%) }\end{array}$ & $\begin{array}{l}\text { Tolerance } \\
\text { limit (\%) }\end{array}$ & $\begin{array}{c}\text { Growth at } \\
12 \% \\
\text { EtOH(\%) }\end{array}$ & $\begin{array}{l}\text { Tolerance } \\
\text { limit }\left(\left.g\right|^{-1}\right)\end{array}$ & $\begin{array}{l}\text { Growth } \\
\text { at } 3 \mathrm{gl}^{-1} \\
\text { HMF (\%) }\end{array}$ & $\begin{array}{l}\text { Tolerance } \\
\text { limit }\left({ }^{\circ} \mathrm{C}\right)\end{array}$ & $\begin{array}{c}\text { Growth } \\
\text { at } 39^{\circ} \mathrm{C} \\
(\%)\end{array}$ & $\begin{array}{l}\text { Theoretical } \\
\text { Yield (\%) }\end{array}$ & $\begin{array}{l}\text { Time } \\
\text { to } \\
\text { reach } \\
\text { Vmax } \\
\text { (h) }\end{array}$ & $\begin{array}{l}\text { C50 } \\
(h)^{(a)}\end{array}$ \\
\hline Y745 & Wild & 50 & 32.4 & 14 & 63.5 & 7 & 66.2 & 41 & 116.9 & 83 & 18.33 & 40.51 \\
\hline Y313 & Wild & 50 & 24.5 & 12 & 25.9 & 7 & 91.7 & 39 & 85.3 & 86 & 20.26 & 40.51 \\
\hline Y314 & Wild & 50 & 22.4 & 13 & 61.6 & 7 & 77.4 & 39 & 161.5 & 83 & 24.12 & 40.51 \\
\hline Y312 & Wild & 50 & 25.5 & 13 & 59.9 & 7 & 75.1 & 39 & 158.6 & 84 & 22.19 & 38.58 \\
\hline Y310 & Wine & 50 & 21.7 & 14 & 45.6 & $<2$ & 0 & 39 & 95.3 & 86 & 18.33 & 36.65 \\
\hline Y224 & Wine & 50 & 28.4 & 14 & 52.3 & 4 & 36 & 39 & 43.8 & 85 & 20.26 & 32.79 \\
\hline Y232 & Wine & 50 & 28.1 & 14 & 51.7 & 4 & 66.8 & 37 & 0 & 85 & 18.33 & 30.86 \\
\hline CAT1 & Bioethanol & 50 & 27.6 & 13 & 56.8 & 2 & 0 & 39 & 40.6 & 88 & 18.33 & 30.86 \\
\hline Ethanol Red & Bioethanol & 50 & 24.1 & 14 & 21.9 & 5 & 128.7 & 39 & 150.3 & 91 & 18.33 & 32.79 \\
\hline$s 288 c$ & Lab & 48 & 9.4 & 12 & 12.5 & $<2$ & 0 & 39 & 27.2 & 78 & 18.33 & 63.67 \\
\hline Y1 & Ale & $<40$ & 0 & 10 & 0 & $<2$ & 0 & 39 & 38.5 & 61 & 31.83 & 79.1 \\
\hline
\end{tabular}

(a) $\mathrm{C} 50$ : Time to consume $50 \%$ of the initial sugar content 
Ale strains were significantly less tolerant to $12 \%$ ethanol $(\mathrm{v} / \mathrm{v})$, while bioethanol strains performed significantly better than the average ethanol tolerance levels of isolates from other origins (Fig. 3). Isolates from all other origins showed no significant difference in ethanol tolerance, however, a large variation of tolerance is observed within each origin, especially for wild isolates (Fig. 3). Some wild isolates even managed to grow at very high ethanol concentrations (14\%). On average, ale strains were also significantly less tolerant to 5-HMF compared to bioethanol, wine, spirit and wild isolates (Fig. 3). A large variation was seen among wild isolates (Fig. 3). Most wine, bioethanol and wild isolates were still able to grow at $4 \mathrm{~g} \mathrm{I}^{-1}$ 5-HMF (91\% (58), 88\% (7) and 83\% (34) respectively). Twelve isolates, of which eight were wild isolates, managed to grow even at $7 \mathrm{~g}^{-1} 5$ HMF.

In order to determine metal tolerance three metals were selected, i.e. $\mathrm{Zn}, \mathrm{Cd}$ and $\mathrm{Cu}$. Results show that no correlation (Table 2) exists between tolerance to $\mathrm{Cu}$ and the two other metals ( $r=0.02-0.04)$, whereas a weak correlation was observed between tolerance to $\mathrm{Cd}$ and $\mathrm{Zn}(\mathrm{r}=0.29)$. On average, no significant difference in tolerance to the reference concentration of $\mathrm{Zn}$ was observed among all origins (Fig. 3). Nevertheless, ale, wild and sake isolates represented most of the isolates (89\%) still able to grow at $6 \mathrm{mM}$ and four ale strains were able to grow up to $8 \mathrm{mM}$. Similarly, no significant differences in average tolerance to $\mathrm{Cd}$ were observed among the isolates from different origins. From $1 \mathrm{mM}$ onwards, growth of all, except five wild isolates, was inhibited. We identified two S. cerevisiae wild isolates that can tolerate up to $2 \mathrm{mM}$ of $\mathrm{CdSO}_{4}$. Results showed that wine strains were most tolerant to $0.1 \mathrm{mM}$ of $\mathrm{Cu}$ with $73 \%$ (47) of the strains that managed to grow and showed significantly higher $\mathrm{Cu}$ tolerance compared to ale, sake, spirit and wild isolates (Fig. 3). Surprisingly, 67\% (6) of the bakery strains also showed considerably high Cu tolerance. We identified $12 \mathrm{~S}$. cerevisiae strains that managed to grow up to $0.3 \mathrm{mM} \mathrm{Cu}$ concentration, from which six originate from the winery environment. 
Table 2: Correlations ${ }^{(a)}$ between different reference concentrations ${ }^{(b)}$ for the S. cerevisiae isolates.

\begin{tabular}{|c|c|c|c|c|c|c|c|c|c|c|c|}
\hline $\begin{array}{c}\text { Glucose } \\
48 \%\end{array}$ & $\begin{array}{c}\text { Fructose } \\
48 \%\end{array}$ & $\begin{array}{c}\text { Sorbitol } \\
44 \%\end{array}$ & $\begin{array}{c}\mathrm{NaCl} \\
1000 \mathrm{mM}\end{array}$ & $\begin{array}{c}\mathrm{KCl} 1500 \\
\mathrm{mM}\end{array}$ & $\begin{array}{c}\mathrm{LiCl} 50 \\
\mathrm{mM}\end{array}$ & ET12\% & T $39^{\circ} \mathrm{C}$ & HMF $3 \mathrm{gl}^{-1}$ & $\begin{array}{l}\mathrm{ZnCl} 2 \\
5 \mathrm{mM}\end{array}$ & $\begin{array}{l}\mathrm{CdSO}_{4} \\
0.5 \mathrm{mM} \\
\end{array}$ & $\begin{array}{c}\mathrm{CuSO}_{4} \\
0.1 \mathrm{mM}\end{array}$ \\
\hline \multirow{12}{*}{$\begin{array}{c}\text { Glucose } \\
48 \%\end{array}$} & 0.84 & 0.78 & 0.14 & 0.42 & 0.15 & 0.56 & 0.41 & 0.47 & -0.01 & 0.22 & 0.10 \\
\hline & $\begin{array}{l}\text { Fructose } \\
48 \%\end{array}$ & 0.85 & 0.18 & 0.52 & 0.13 & 0.47 & 0.38 & 0.37 & 0.00 & 0.16 & 0.06 \\
\hline & & $\begin{array}{l}\text { Sorbitol } \\
44 \%\end{array}$ & 0.14 & 0.52 & 0.10 & 0.45 & 0.38 & 0.34 & 0.08 & 0.19 & 0.02 \\
\hline & & & $\begin{array}{c}\mathrm{NaCl} \\
1000 \mathrm{mM}\end{array}$ & 0.21 & 0.72 & 0.31 & 0.27 & -0.01 & -0.23 & -0.09 & 0.11 \\
\hline & & & & $\begin{array}{c}\mathrm{KCl} 1500 \\
\mathrm{mM}\end{array}$ & 0.22 & 0.34 & 0.30 & 0.21 & 0.07 & 0.16 & -0.09 \\
\hline & & & & & $\begin{array}{c}\text { LiCl } 50 \\
\text { mM }\end{array}$ & 0.34 & 0.30 & 0.05 & -0.32 & -0.08 & 0.05 \\
\hline & & & & & & ET12\% & 0.58 & 0.40 & -0.16 & 0.18 & 0.21 \\
\hline & & & & & & & $\mathrm{T} 39^{\circ} \mathrm{C}$ & 0.36 & -0.16 & 0.21 & 0.08 \\
\hline & & & & & & & & HMF $3 \mathrm{gl}^{-1}$ & 0.05 & 0.40 & 0.18 \\
\hline & & & & & & & & & $\begin{array}{l}\mathrm{ZnCl}{ }_{2} \\
5 \mathrm{mM}\end{array}$ & 0.29 & 0.02 \\
\hline & & & & & & & & & & $\begin{array}{l}\mathrm{CdSO}_{4} \\
0.5 \mathrm{mMM}\end{array}$ & 0.04 \\
\hline & & & & & & & & & & & $\begin{array}{c}\mathrm{CuSO}_{4} \\
0.1 \mathrm{mM}\end{array}$ \\
\hline
\end{tabular}

(a) All significant trait correlations $(p<0.05)$ are indicated with black font color. Correlations that are not significant are indicated with red font color. Cells with larger correlation values are colored blue, while cells with smaller values are colored green to yellow. Cells with the smallest value are colored red.

(b) concentration at which approximately $50 \%$ of the investigated strains managed to grow and showed the highest coefficient of variation (Supplementary Material Table S2). 
Potential of selected multitolerant Saccharomyces cerevisiae strains in first and second-generation bioethanol fermentations

To validate the potential of the obtained dataset for selection of industrially applicable Saccharomyces strains, two proof-of-principle experiments, aiming at the identification of strains suitable for first and/or second generation bioethanol production were conducted. Fermentation assays in simulated $1^{\text {st }}$ generation high gravity bioethanol production medium allowed us to compare the ethanol productivity and fermentation efficiency of the seven selected multitolerant strains (Table 3). Ethanol Red yielded most ethanol and produced $91 \%$ of the theoretical ethanol yield, followed by CAT1 which produced $88 \%$ of the theoretical yield. The ethanol yields of the selected multitolerant strains were comparable ( $83 \%-86 \%$ of the theoretical ethanol yield). However, strains Y312 and Y232 were the fastest in consuming 50\% of the starting sugar concentration among the tested wild and wine strains, respectively (Table 3 ). These two strains were therefore subjected to a fermentation mimicking a second-generation bioethanol fermentation of lignocellulose hydrolysate containing multiple inhibitors and $12 \%$ glucose (w/v) (Fig. 4A). In these conditions, the industrial bioethanol strain CAT1 needed nearly $47 \mathrm{~h}$ to consume $50 \%$ of the sugars, while Ethanol Red and Y232 were significantly faster ( $23 \mathrm{~h}$ and $25 \mathrm{~h}$, respectively). Strain Y312 was also significantly faster than CAT1, but slower than Ethanol Red and Y232. The HPLC analysis after completion of the fermentation indicated that the ethanol yield was nearly $100 \%$ of the theoretical yield for all four strains (Table 4). No significant differences were found between these strains in terms of fermentation performance in $12 \%$ glucose without inhibitors (Fig. 4B).

\section{Discussion}

In this study, a broad collection of genetically diverse Saccharomyces yeasts, belonging to four different species (namely S. cerevisiae, S. paradoxus, S. pastorianus, and S. bayanus) and originating from different industrial and natural habitats, was phenotyped on six selective traits relevant for bioethanol production, including osmotic, thermal, ethanol, salt, heavy metal and 5-HMF stress. Our results demonstrate a remarkably large phenotypic diversity among different Saccharomyces species and among S. cerevisiae isolates from different origins, extending the results of Kvitek et al. (2008), Skelly et al. (2013), and Warringer et al. (2011).

Hyperosmotic stress tolerance of $S$. cerevisiae and the molecular basis behind it has been investigated extensively. In hyperosmostress tolerance studies, Saccharomyces yeasts have been generally subjected to hypertonic growth conditions using glucose or sorbitol as the solute (Tokuoka 1993; Tedrick et al. 2004; Dudley et al. 2005; Watanabe et al. 2010). Additionally, in a few cases, osmostress tolerance has also been evaluated using $\mathrm{NaCl}$ or $\mathrm{KCl}$ as the solute (Babazadeh et al. 2013; 
A

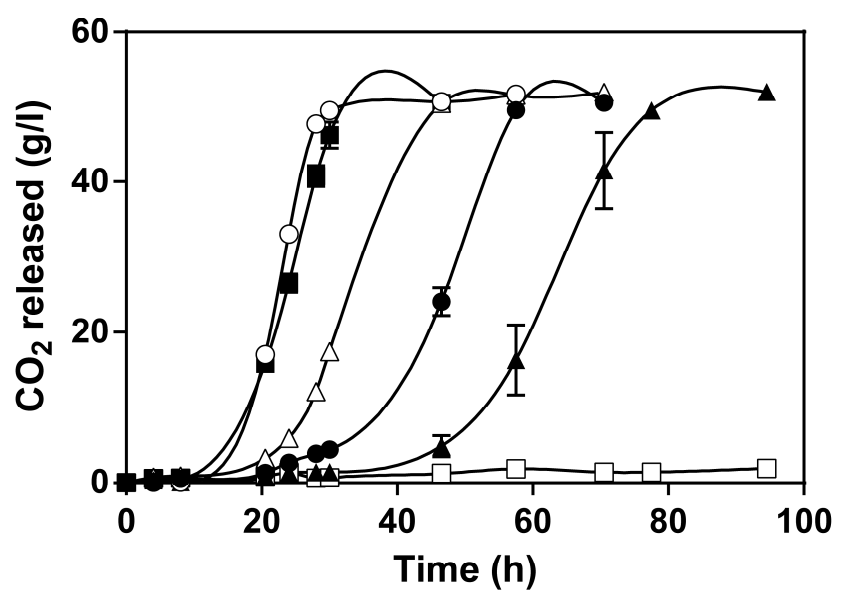

B

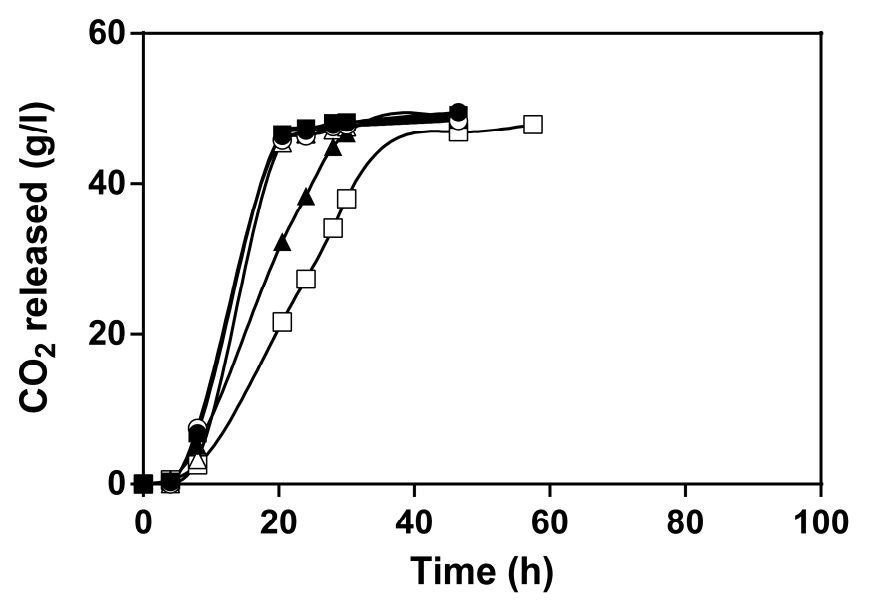

Fig. 4: Panel A: Fermentation efficiency of multitolerant yeast strains at $12 \%(\mathrm{w} / \mathrm{v})$ glucose with inhibitor cocktail containing $1.02 \mathrm{~g} \mathrm{I}^{-1}$ 5-HMF, $0.33 \mathrm{~g} \mathrm{I}^{-1}$ furfural, $1.9 \mathrm{~g} \mathrm{I}^{-1}$ acetic acid, $0.36 \mathrm{~g} \mathrm{I}^{-1}$ formic acid, $0.7 \mathrm{~g} \mathrm{I}^{-1}$ levulinic acid and $0.033 \mathrm{~g} \mathrm{I}^{-1}$ vanillin. Panel B: Fermentation efficiency of multitolerant yeast strains in the absence of inhibitors. CAT $1(\bullet)$, Ethanol Red (o), $\operatorname{S288c}(\mathbf{\Delta})$, Y312 ( $\triangle)$, Y232 (ロ), Y1 (). 
Table 4: Fermentation performance of multitolerant strains $Y 232$ and $Y 312$, bioethanol strains CAT1 and Ethanol Red and sensitive strains S288c and Y1 in fermentations with $12 \%$ glucose $(\mathrm{w} / \mathrm{v})$ in the presence and absence of the inhibitor cocktail ${ }^{(a)}$.

\begin{tabular}{|c|c|c|c|c|c|c|c|c|}
\hline & \multicolumn{4}{|c|}{$12 \%$ glucose } & \multicolumn{4}{|c|}{$12 \%$ glucose + Inhibitor } \\
\hline & $\begin{array}{l}\text { Ethanol } \\
\text { yield/ } 100 \mathrm{~g} \\
\text { of sugar }\end{array}$ & $\begin{array}{l}\text { Theoretical } \\
\text { Yield (\%) }\end{array}$ & $\begin{array}{l}\text { Time to } \\
\text { reach } \\
\text { Vmax } \\
\text { (h) }\end{array}$ & $\begin{array}{l}\text { C50 } \\
(h)^{(b)}\end{array}$ & $\begin{array}{c}\text { Ethanol } \\
\text { yield/ } 100 \mathrm{~g} \\
\text { of sugar }\end{array}$ & $\begin{array}{l}\text { Theoretica } \\
\text { I Yield (\%) }\end{array}$ & $\begin{array}{l}\text { Time to } \\
\text { reach } \\
\text { Vmax } \\
\text { (h) }\end{array}$ & $\begin{array}{l}\text { C50 } \\
(h)^{(b)}\end{array}$ \\
\hline CAT1 & 49.33 & 96 & 13.07 & 13.35 & 48.58 & 95 & 50.11 & 48.68 \\
\hline Ethanol Red & 49.02 & 96 & 12.49 & 13.35 & 51.48 & 101 & 23.39 & 22.91 \\
\hline Y232 & 50.46 & 99 & 13.07 & 13.35 & 50.17 & 98 & 25.30 & 24.81 \\
\hline Y312 & 50.44 & 99 & 13.65 & 14.52 & 48.29 & 94 & 31.02 & 34.36 \\
\hline S288c & 51.37 & 100 & 14.81 & 17.42 & 49.52 & 97 & 63.48 & 63.95 \\
\hline Y1 & 48.23 & 94 & 17.71 & 23.23 & 2.10 & 4 & 21.48 & NA \\
\hline
\end{tabular}

Pastor et al. 2009; Yoshikawa et al. 2009). Interestingly, the genome expression study of Causton et al. (2001) demonstrated remarkable similarity in yeast response between high salt and high sorbitol concentration and therefore suggested that the change in yeast gene expression under high salt concentration is due to the change in osmotic conditions. However, in our study sugar tolerance poorly correlated with $\mathrm{NaCl}$ and $\mathrm{LiCl}$ tolerance and only moderately with $\mathrm{KCl}$ tolerance. This suggests that tolerance to these solutes might be driven by (partially) different mechanisms. In line with this hypothesis, it has been shown that stress due to high $\mathrm{NaCl}$, $\mathrm{LiCl}$ or $\mathrm{KCl}$ concentrations is not primarily due to hyperosmotic stress, but rather to the toxicity of high intracellular cation concentrations (Mulet et al. 1999). In line with previous studies (Mulet et al. 1999; Pastor et al. 2009) we also observed that the thresholds of intracellular toxicity for these monovalent cations differ from one another where $\mathrm{Li}^{+}$has been identified as the most potent stressor followed by $\mathrm{Na}^{+}$and $\mathrm{K}^{+}$.

In general, S. pastorianus was the least tolerant Saccharomyces species tested, especially for osmotic, ethanol and 5-HMF stress. This might be partly explained by the fact that $S$. pastorianus is mainly used in and adapted to low temperatures in mild lager beer fermentation conditions (Baerends et al. 2009; Peris et al. 2011; Sanchez et al. 2012), while tests here were performed at 30 ${ }^{\circ} \mathrm{C}$. Despite having considerably higher genetic diversity, S. paradoxus is often reported to have less phenotypic diversity in comparison to its domesticated relative S. cerevisiae (Liti et al. 2009; Warringer et al. 2011). Contrary to these studies, the S. paradoxus isolates tested in this study (38 isolates) did not show any overall significant difference in phenotypic diversity compared to the $S$. 
cerevisiae isolates. Differences in the stressors evaluated, the evaluation method and the strain collections studied might explain this discrepancy between the present study and the previous studies. However, when we consider individual traits, we found that for some traits, S. paradoxus isolates have significantly lower phenotypic diversity compared to S. cerevisiae isolates. However, it has to be emphasized that in this study the $S$. cerevisiae isolates set was considerably larger than that of S. paradoxus.

Both S. paradoxus and S. bayanus have been reported previously as less tolerant to ethanol (Arroyo-López et al. 2010) and less thermotolerant (Gonçalves et al. 2011) compared to S. cerevisiae. In agreement with these findings, S. cerevisiae performed significantly better than S. paradoxus also in this study. However, S. bayanus performed as well as S. cerevisiae in both ethanol and thermal stress conditions. This might be explained by the fact that $S$. bayanus strains in this collection mainly originated from wine fermentations (seven strains out of ten). This might introduce a bias for the high temperature and especially the ethanol tolerance.

Within the domesticated S. cerevisiae isolates, our results showed that ale strains showed significantly higher phenotypic diversity than isolates from other origins (except sake). This may be explained by the pervasive poly- and aneuploidy of ale beer strains (Legras et al. 2007; Querol and Bond 2009), that may confer phenotypic plasticity under different environmental conditions (Comai 2005). The phenotypic diversity of sake strains was as wide as that of ale strains $(p=0.374)$. This is caused by the fact that the sake strains investigated are mostly either sensitive or very tolerant to the different environmental conditions assayed in this study, which is in line with the findings of Kvitek et al. (2008).

Within the set of $S$. cerevisiae isolates, phenotypic variability among the non-domesticated $S$. cerevisiae isolates was found to be more or less similar to that of the domesticated S. cerevisiae. Interestingly, S. cerevisiae strains from wine and bioethanol production as well as the wild isolates investigated, generally showed considerable tolerance to most of the traits (Fig. 3). On the contrary, ale beer strains appeared to be the least tolerant to the conditions tested. Moreover, the performances of wild S. cerevisiae isolates were often equally good or sometimes even significantly better compared to the isolates from domesticated origins (wine, sake, bakery, spirit and ale). This suggests that domestication events specific for these origins did not contribute any improvements over these traits during the course of centuries-long evolution. This agrees with the hypothesis that domestication events do not greatly influence the phenotypic diversity among the $S$. cerevisiae population (Liti et al. 2009). Treu et al. (2014) also suggested that domestication events are not always crucial as they showed that many wild vineyard isolates own appropriate phenotypic characteristics for wine fermentation. As an exception, results showed that $73 \%$ of wine isolates 
were tolerant to $0.1 \mathrm{mM}$ of $\mathrm{Cu}$. Kvitek et al. (2008) suggested that $\mathrm{Cu}$ tolerance might have evolved in wine isolates through positive selection as copper is traditionally used in the vineyards and orchards as antimicrobial agent. Warringer et al. (2011) demonstrated a strong association of the sake lineage with a copy number variation of the copper binding metallothionein CUP1 gene, which could explain the high $\mathrm{Cu}$ tolerance of sake strains, a result confirmed in this study. Interestingly, also baker's yeasts were found to be exceptionally tolerant to copper. Since these strains are traditionally not associated with high copper stress, this peculiar phenotype might be explained by the historical origin of baker's yeast. It was recently proposed that most modern baker's yeast strains result from an allotetroploidization event between an ale and a wine yeast (Randez-Gilet al. 2013). Therefore, genetic inheritance of the wine strain's high copper tolerance could explain this phenotype.

In addition to this phenotypic variability analysis this dataset allows selection of multitolerant strains suited for bioethanol production. Not surprisingly currently used bioethanol strains were in general considerably tolerant to multiple stress factors (osmotolerance, ethanol tolerance, thermotolerance, 5-HMF tolerance). However, we also identified multitolerant isolates from other origins that sometimes even outperformed the bioethanol strains for certain traits. Therefore, we hypothesized that these multitolerant strains coming from other origins might have great potential for commercial bioethanol production. In order to validate this hypothesis two proof-of-principle fermentation experiments were conducted. The first experiment at $33 \%$ glucose indicated that in terms of ethanol yield, all the tested multitolerant strains performed nearly as well as industrial strain CAT1. However, Ethanol Red outcompeted all other strains and was clearly superior in conditions mimicking first-generation bioethanol production. Nevertheless, in a second fermentation mimicking the harsh conditions in lignocellulose hydrolysates by addition of fermentation inhibitors, the strain Y232 (originating from wine) showed to be as efficient as Ethanol Red and better than CAT1. The wild strain Y312 also outperformed CAT1.

Together, this large-scale and high-throughput phenotypic analysis yielded a multi-purpose database, providing novel insights in general inter- and intra-species phenotypic diversity of Saccharomyces yeasts. Additionally, it provides a basis for new insights into the relationships between tolerance to different stressors. Our results also illustrate the potential of phenotypically evaluating the natural biodiversity of yeasts to find superior industrial strains that may be used in bioethanol production. In addition, it may provide excellent candidates for further strain improvement through genetic engineering, experimental evolution, or breeding. 


\section{References}

Abramoff MD, Magalhães, PJ, Ram, SJ (2004) Image processing with ImageJ. Biophotonics Intern $11: 36-42$

Almeida JR, Runquist D, Sànchez Nogué V, Lidén G, Gorwa-Grauslund MF (2011) Stress-related challenges in pentose fermentation to ethanol by the yeast Saccharomyces cerevisiae. Biotechnol J 6:286-299 doi:10.1002/biot.201000301

Almeida JRM, Modig T, Petersson A, Hahn-Hägerdal B, Lidén G, Gorwa-Grauslund MF (2007) Increased tolerance and conversion of inhibitors in lignocellulosic hydrolysates by Saccharomyces cerevisiae. J Chem Technol Biotechnol 82:340-349 doi:10.1002/jctb.1676

Arroyo-López FN, Salvado Z, Tronchoni J, Guillamón JM, Barrio E, Querol A (2010) Susceptibility and resistance to ethanol in Saccharomyces strains isolated from wild and fermentative environments. Yeast 27:1005-1015 doi:10.1002/yea.1809

Babazadeh R, Adiels CB, Smedh M, Petelenz-Kurdziel E, Goksör M, Hohmann S (2013) Osmostressinduced cell volume loss delays yeast Hog1 signaling by limiting diffusion processes and by Hog1specific effects. PLoS ONE 8:e80901 doi:10.1371/journal.pone.0080901

Baerends RJ, Qiu JL, Rasmussen S, Nielsen HB, Brandt A (2009) Impaired uptake and/or utilization of leucine by Saccharomyces cerevisiae is suppressed by the SPT15-300 allele of the TATA-binding protein gene. Appl Environ Microbiol 75:6055-6061 doi:10.1128/AEM.00989-09

Basso LC, de Amorim HV, de Oliveira AJ, Lopes ML (2008) Yeast selection for fuel ethanol production in Brazil. FEMS Yeast Res 8:1155-1163 doi:10.1111/j.1567-1364.2008.00428.x

Basso LC, Basso TO, Rocha SN (2011) Ethanol production in Brazil: the industrial process and its impact on yeast fermentation. In: dos Santos Bernardes MA (ed) Biofuel production-Recent developments and prospects. InTech, Rijeka, Croatia, doi: 10.5772/17047

Bokulich NA, Thorngate JH, Richardson PM, Mills DA (2014) Microbial biogeography of wine grapes is conditioned by cultivar, vintage, and climate. Proc Natl Acad Sci USA 111:E139-148 doi:10.1073/pnas.1317377110

Causton HC, Ren B, Koh SS, Harbison CT, Kanin E, Jennings EG, Lee TI, True HL, Lander ES, Young RA (2001) Remodeling of yeast genome expression in response to environmental changes. Mol Biol Cell 12:323-337 doi:10.1091/mbc.12.2.323 
Chen X, Shekiro J, Franden MA, Wang W, Zhang M, Kuhn E, Johnson DK, Tucker MP (2012) The impacts of deacetylation prior to dilute acid pretreatment on the bioethanol process. Biotechnol Biofuels 5:8 doi:10.1186/1754-6834-5-8

Comai L (2005) The advantages and disadvantages of being polyploidy. Nat Rev Genet 6:836-846 doi:10.1038/nrg1711

Conant GC, Wolfe KH (2007) Increased glycolytic flux as an outcome of whole-genome duplication in yeast. Mol Syst Biol 3:129 doi:10.1038/msb4100170

da Silva-Filho EA, Brito dos Santos SK, Resende Ado M, de Morais JO, de Morais MA Jr, Ardaillon Simões D (2005) Yeast population dynamics of industrial fuel-ethanol fermentation process assessed by PCR-fingerprinting. Antonie van Leeuwenhoek 88:13-23 doi:10.1007/s10482-004-7283-8

Demeke MM, Dietz H, Li Y, Foulquié-Moreno MR, Mutturi S, Deprez S, Abt TD, Bonini BM, Lidén G, Dumortier F, Verplaetse A, Boles E, Thevelein JM (2013) Development of a D-xylose fermenting and inhibitor tolerant industrial Saccharomyces cerevisiae strain with high performance in lignocellulose hydrolysates using metabolic and evolutionary engineering. Biotechnol Biofuels 6:89doi:10.1186/1754-6834-6-89

Diezmann S, Dietrich FS (2009) Saccharomyces cerevisiae: population divergence and resistance to oxidative stress in clinical, domesticated and wild strains. PLoS ONE 4:e5317 doi:10.1371/journal.pone.0005317

Dittmar JC, Reid RJ, Rothstein R (2010) ScreenMill: a freely available software suite for growth measurement, analysis and visualization of high-throughput screen data. BMC Bioinfo 11:353 doi:10.1186/1471-2105-11-353

Dudley AM, Janse DM, Tanay A, Shamir R, Church GM (2005) A global view of pleiotropy and phenotypically derived gene function in yeast. Mol Syst Biol 1:2005.0001 doi:10.1038/msb4100004

Fay JC, Benavides JA (2005) Evidence for domesticated and wild populations of Saccharomyces cerevisiae. PLoS Genet 1:66-71 doi:10.1371/journal.pgen.0010005

Garcia Sanchez R, Solodovnikova N, Wendland J (2012) Breeding of lager yeast with Saccharomyces cerevisiae improves stress resistance and fermentation performance. Yeast 29:343-355 doi:10.1002/yea.2914

Goddard MR (2008) Quantifying the complexities of Saccharomyces cerevisiae's ecosystem engineering via fermentation. Ecology 89:2077-2082 doi:10.1890/07-2060.1 
Gonçalves P, Valerio E, Correia C, de Almeida JM, Sampaio JP (2011) Evidence for divergent evolution of growth temperature preference in sympatric Saccharomyces species. PLoS ONE 6:e20739 doi:10.1371/journal.pone.0020739

Hubmann G, Mathe L, Foulquié-Moreno MR, Duitama J, Nevoigt E, Thevelein JM (2013) Identification of multiple interacting alleles conferring low glycerol and high ethanol yield in Saccharomyces cerevisiae ethanolic fermentation. Biotechnol Biofuels 6:87 doi:10.1186/1754-6834-6-87

Hyma KE, Saerens SM, Verstrepen KJ, Fay JC (2011) Divergence in wine characteristics produced by wild and domesticated strains of Saccharomyces cerevisiae. FEMS Yeast Res 11:540-551 doi:10.1111/j.1567-1364.2011.00746.x

Jin M, Sarks C, Gunawan C, Bice BD, Simonett SP, Narasimhan RA, Willis LB, Dale BE, Balan V, Sato TK (2013) Phenotypic selection of a wild Saccharomyces cerevisiae strain for simultaneous saccharification and co-fermentation of AFEXTM pretreated corn stover. Biotechnol Biofuels 6:108doi:10.1186/1754-6834-6-108

Kane SM, Roth R (1974) Carbohydrate metabolism during ascospore development in yeast. J Bacteriol 118:8-14

Koppram R, Albers E, Olsson L (2012) Evolutionary engineering strategies to enhance tolerance of xylose utilizing recombinant yeast to inhibitors derived from spruce biomass. Biotechnol Biofuels 5:32 doi:10.1186/1754-6834-5-32

Kumar S, Dheeran P, Singh SP, Mishra IM, Adhikari DK (2013) Cooling system economy in ethanol production using thermotolerant yeast Kluyveromyces Sp. IIPE453. Am J Microbiol Res 1:39-44 doi:10.12691/ajmr-1-3-1

Kumari R, Pramanik K (2012) Improvement of multiple stress tolerance in yeast strain by sequential mutagenesis for enhanced bioethanol production. J Biosci Bioeng 114:622-629 doi:10.1016/j.jbiosc.2012.07.007

Kurtzman CP, Robnett CJ (1997) Identification of clinically important ascomycetous yeasts based on nucleotide divergence in the 5 ' end of the large-subunit (26S) ribosomal DNA gene. J Clin Microbiol $35: 1216-1223$

Kvitek DJ, Will JL, Gasch AP (2008) Variations in stress sensitivity and genomic expression in diverse $S$. cerevisiae strains. PLoS Genet 4:e1000223 doi:10.1371/journal.pgen.1000223

Legras JL, Karst F (2003) Optimisation of interdelta analysis for Saccharomyces cerevisiae strain characterisation. FEMS Microbiol Lett 221:249-255 doi:10.1016/s0378-1097(03)00205-2 
Legras JL, Merdinoglu D, Cornuet JM, Karst F (2007) Bread, beer and wine: Saccharomyces cerevisiae diversity reflects human history. Mol Ecol 16:2091-2102 doi:10.1111/j.1365-294X.2007.03266.x

Liti G, Carter DM, Moses AM, Warringer J, Parts L, James SA, Davey RP, Roberts IN, Burt A, Koufopanou V, Tsai IJ, Bergman CM, Bensasson D, O'Kelly MJT, van Oudenaarden A, Barton DBH, Bailes E, Ba ANN, Jones M, Quail MA, Goodhead I, Sims S, Smith F, Blomberg A, Durbin R, Louis EJ (2009) Population genomics of domestic and wild yeasts. Nature 458:337-341 doi:10.1038/nature07743

Meersman E, Steensels J, Mathawan M, Wittocx PJ, Saels V, Struyf N, Bernaert H, Vrancken G, Verstrepen KJ (2013) Detailed analysis of the microbial population in Malaysian spontaneous cocoa pulp fermentations reveals a core and variable microbiota. PLoS ONE 8:e81559 doi:10.1371/journal.pone.0081559

Mortimer RK, Johnston JR (1986) Genealogy of principal strains of the yeast genetic stock center. Genetics 113:35-43

Mulet JM, Leube MP, Kron SJ, Rios G, Fink GR, Serrano R (1999) A novel mechanism of ion homeostasis and salt tolerance in yeast: the Hal4 and Hal5 protein kinases modulate the Trk1-Trk2 potassium transporter. Mol Cell Biol 19:3328-3337

Novo M, Bigey F, Beyne E, Galeote V, Gavory F, Mallet S, Cambon B, Legras JL, Wincker P, Casaregola S, Dequin S (2009) Eukaryote-to-eukaryote gene transfer events revealed by the genome sequence of the wine yeast Saccharomyces cerevisiae EC1118. Proc Natl Acad Sci USA 106:16333-16338 doi:10.1073/pnas.0904673106

Pais TM, Foulquié-Moreno MR, Hubmann G, Duitama J, Swinnen S, Goovaerts A, Yang Y, Dumortier F, Thevelein JM (2013) Comparative polygenic analysis of maximal ethanol accumulation capacity and tolerance to high ethanol levels of cell proliferation in yeast. PLoS Genet 9:e1003548 doi:10.1371/journal.pgen.1003548

Palmqvist E, Hahn-Hägerdal B (2000) Fermentation of lignocellulosic hydrolysates. II: inhibitors and mechanisms of inhibition. Bioresour Technol 74:25-33 doi:http://dx.doi.org/10.1016/S09608524(99)00161-3

Pando Bedriñana R, Querol Simón A, Suárez Valles B (2010) Genetic and phenotypic diversity of autochthonous cider yeasts in a cellar from Asturias. Food Microbiol 27:503-508 doi:10.1016/j.fm.2009.11.018

Pastor MM, Proft M, Pascual-Ahuir A (2009) Mitochondrial function is an inducible determinant of osmotic stress adaptation in yeast. J Biol Chem 284:30307-30317 doi:10.1074/jbc.M109.050682 
Pereira FB, Romani A, Ruiz HA, Teixeira JA, Domingues L (2014) Industrial robust yeast strains with great potential for fermentation of lignocellulosic biomass. Bioresour Technol 161 192-199; 10.1016/j.biortech.2014.03.043

Peris D, Belloch C, Lopandić K, Álvarez-Pérez JM, Querol A, Barrio E (2011) The molecular characterization of new types of Saccharomyces cerevisiae x S. kudriavzevii hybrid yeasts unveils a high genetic diversity. Yeast doi:10.1002/yea.2891

Pinel D, D'Aoust F, del Cardayre SB, Bajwa PK, Lee H, Martin VJ (2011) Saccharomyces cerevisiae genome shuffling through recursive population mating leads to improved tolerance to spent sulfite liquor. Appl Environ Microbiol 77:4736-4743 doi:10.1128/AEM.02769-10

Piškur J, Rozpędowska E, Polakova S, Merico A, Compagno C (2006) How did Saccharomyces evolve to become a good brewer? Trends Genet 22:183-186 doi:10.1016/j.tig.2006.02.002

Pretorius IS (2000) Tailoring wine yeast for the new millennium: novel approaches to the ancient art of winemaking. Yeast 16:675-729 doi:10.1002/1097-0061(20000615)16:8<675::aid-yea585>3.0.co;2b

Puligundla P, Smogrovicova D, Obulam VSR, Ko S (2011) Very high gravity (VHG) ethanolic brewing and fermentation: a research update. J Ind Microbiol Biotechnol 38:1133-1144 doi:10.1007/s10295011-0999-3

Querol A, Bond U (2009) The complex and dynamic genomes of industrial yeasts. FEMS Microbiol Lett 293:1-10 doi:10.1111/j.1574-6968.2008.01480.x

R Core Team (2013) R: A language and environment for statistical computing. R Foundation for Statistical Computing, Vienna, Austria. ISBN 3-900051-07-0 http://www.R-project.org/ 15/03/2014

Ramos CL, Duarte WF, Freire AL, Dias DR, Eleutherio ECA, Schwan RF (2013) Evaluation of stress tolerance and fermentative behavior of indigenous Saccharomyces cerevisiae. Braz J Microbiol 44:935-944.

Randez-Gil F, Córcoles-Sáez I, Prieto JA (2013) Genetic and phenotypic characteristics of baker's yeast: relevance to baking. Annu Rev Food Sci Technol 4:191-214 doi:10.1146/annurev-food-030212182609

Shi DJ, Wang CL, Wang KM (2009) Genome shuffling to improve thermotolerance, ethanol tolerance and ethanol productivity of Saccharomyces cerevisiae. J Ind Microbiol Biotechnol 36:139-147 doi:10.1007/s10295-008-0481-z 
Skelly DA, Merrihew GE, Riffle M, Connelly CF, Kerr EO, Johansson M, Jaschob D, Graczyk B, Shulman NJ, Wakefield J, Cooper SJ, Fields S, Noble WS, Muller EGD, Davis TN, Dunham MJ, MacCoss MJ, Akey JM (2013) Integrative phenomics reveals insight into the structure of phenotypic diversity in budding yeast. Genome Res 23:1496-1504 doi:10.1101/gr.155762.113

Steensels J, Snoek T, Meersman E, Nicolino MP, Voordeckers K, Verstrepen KJ (2014) Improving industrial yeast strains: exploiting natural and artificial diversity. FEMS Microbiol Rev doi:10.1111/1574-6976.12073

Steensels J, Verstrepen KJ (2014) Taming wild yeast: potential of conventional and nonconventional yeasts in industrial fermentations. Annu rev microbiol doi:10.1146/annurev-micro-091213-113025

Swinnen S, Schaerlaekens K, Pais T, Claesen J, Hubmann G, Yang Y, Demeke M, Foulquié-Moreno MR, Goovaerts A, Souvereyns K, Clement L, Dumortier F, Thevelein JM (2012) Identification of novel causative genes determining the complex trait of high ethanol tolerance in yeast using pooledsegregant whole-genome sequence analysis. Genome Res 22:975-984 doi:10.1101/gr.131698.111

Tao X, Zheng D, Liu T, Wang P, Zhao W, Zhu M, Jiang X, Zhao Y, Wu X (2012) A novel strategy to construct yeast Saccharomyces cerevisiae strains for very high gravity fermentation. PLoS ONE 7:e31235 doi:10.1371/journal.pone.0031235

Taylor MP, Mulako I, Tuffin M, Cowan D (2012) Understanding physiological responses to pretreatment inhibitors in ethanologenic fermentations. Biotechnol J 7:1169-1181 doi:10.1002/biot.201100335

Tedrick K, Trischuk T, Lehner R, Eitzen G (2004) Enhanced membrane fusion in sterol-enriched vacuoles bypasses the Vrp1p requirement. Mol Biol Cell 15:4609-4621 doi:10.1091/mbc.E04-03-0194 Thomson JM, Gaucher EA, Burgan MF, De Kee DW, Li T, Aris JP, Benner SA (2005) Resurrecting ancestral alcohol dehydrogenases from yeast. Nat Genet 37:630-635 doi:10.1038/ng1553

Tokuoka K (1993) Sugar- and salt-tolerant yeasts. J Appl Bacteriol 74:101-110 doi:10.1111/j.13652672.1993.tb03002.x

Treu L, Toniolo C, Nadai C, Sardu A, Giacomini A, Corich V, Campanaro S (2014) The impact of genomic variability on gene expression in environmental Saccharomyces cerevisiae strains. Environ Microbiol 16:1378-1397 doi:10.1111/1462-2920.12327

Verstrepen KJ, Derdelinckx G, Verachtert H, Delvaux FR (2003) Yeast flocculation: what brewers should know. Appl Microbiol Biotechnol 61:197-205 doi:10.1007/s00253-002-1200-8

Voordeckers K, Brown CA, Vanneste K, van der Zande E, Voet A, Maere S, Verstrepen KJ (2012) Reconstruction of ancestral metabolic enzymes reveals molecular mechanisms underlying 
evolutionary innovation through gene duplication. PLoS Biol 10:e1001446 doi:10.1371/journal.pbio.1001446

Warringer J, Zorgo E, Cubillos FA, Zia A, Gjuvsland A, Simpson JT, Forsmark A, Durbin R, Omholt SW, Louis EJ, Liti G, Moses A, Blomberg A (2011) Trait variation in yeast is defined by population history. PLoS Genet 7:e1002111 doi:10.1371/journal.pgen.1002111

Watanabe T, Srichuwong S, Arakane M, Tamiya S, Yoshinaga M, Watanabe I, Yamamoto M, Ando A, Tokuyasu K, Nakamura T (2010) Selection of stress-tolerant yeasts for simultaneous saccharification and fermentation (SSF) of very high gravity (VHG) potato mash to ethanol. Bioresour Technol 101:9710-9714 doi:10.1016/j.biortech.2010.07.079

Wimalasena TT, Greetham D, Marvin ME, Liti G, Chandelia Y, Hart A, Louis EJ, Phister TG, Tucker GA, Smart KA (2014) Phenotypic characterisation of Saccharomyces spp. yeast for tolerance to stresses encountered during fermentation of lignocellulosic residues to produce bioethanol. Microb Cell Fact 13:47 doi:10.1186/1475-2859-13-47

Yoshikawa K, Tanaka T, Furusawa C, Nagahisa K, Hirasawa T, Shimizu H (2009) Comprehensive phenotypic analysis for identification of genes affecting growth under ethanol stress in Saccharomyces cerevisiae. FEMS Yeast Res 9:32-44 doi:10.1111/j.1567-1364.2008.00456.x 